\title{
ESPÉCIES FLORESTAIS UTILIZADAS EM UM REFLORESTAMENTO PARA COMPOSIÇÃO DE RESERVA LEGAL PARA MANEJO SUSTENTADO EM PRESIDENTE PRUDENTE - SP
}

\author{
Renato de Araújo Ferreira', Plínio Carielo, João Luiz Dal Ponte Filho', Ítalo Afonso Alves Moura² \\ Centro Estadual de Educação Tecnológica Paula Souza, Escola Técnica Estadual Prof. Dr. Antonio Eufrásio de Toledo - \\ ETEC, Curso Técnico em Florestas, Presidente Prudente, SP. E-mail: renato.ferreira26@etec.sp.gov.br
}

\section{RESUMO}

Por lei, toda a propriedade rural deve ter regularizada a Reserva Legal. As propriedades rurais que não se encontram regularizadas podem fazê-lo por meio do plantio de mudas. No entanto, existem critérios no ato da escolha das espécies e na quantidade de indivíduos por espécie, visando obter um povoamento florestal com o mínimo de condições para ter biodiversidade. Dessa forma, o presente trabalho teve como objetivo realizar o levantamento das espécies florestais recém implantadas em área de Reserva Legal experimental. $O$ trabalho foi realizado na Escola Técnica Estadual Prof. Dr. Antonio Eufrásio de Toledo, em setembro de 2014. Após o levantamento constatou-se 278 indivíduos arbóreos, sendo 173 indivíduos de espécies nativas da região (62\%), intercalados com 105 indivíduos de espécies não nativas regionais (38\%). Concluído o levantamento, observa-se que o reflorestamento está em acordo com a legislação ambiental noS âmbitoS federal e estadual, desempenhando dessa forma seu papel ecológico, social e econômico. Palavras - chave: Espécies, diversidade, densidade, biodiversidade

\section{FOREST SPECIES USED IN A REFORESTATION FOR COMPOSITION OF LEGAL RESERVE FOR SUSTAINED MANAGEMENT AT PRESIDENTE PRUDENTE - SP}

\begin{abstract}
By law, all rural property must have regularized the legal reserve. The farms that are not regulated, can do so by planting seedlings. However there are criteria in the act of choice of species and number of individuals per species, to obtain a forest stand with minimal conditions to have biodiversity. Thus, the present study aimed to conduct survey of forest species newly implanted in experimental legal reserve area. The study was conducted at the State Technical School Professor Dr. Antonio Eufrásio of Toledo in September 2014. After survey found up 278 individual trees, with 173 individuals of native species (62\%), interspersed with 105 individuals from non-regional native species (38\%). It completed the survey it was observed that reforestation is in accordance with environmental legislation at the federal and state level, thereby performing ecological, social and economic role.
\end{abstract}

Keywords: Species diversity, density, biodiversity 


\section{INTRODUÇÃO}

Segundo o artigo 3o, inciso III, da Lei 12.651 de 25 de maio de 2012, Reserva Legal é definida como "área localizada no interior de uma propriedade ou posse rural, delimitada nos termos do art. 12, com a função de assegurar o uso econômico de modo sustentável dos recursos naturais do imóvel rural, auxiliar a conservação e a reabilitação dos processos ecológicos $e$ promover a conservação da biodiversidade, bem como o abrigo e a proteção de fauna silvestre $e$ da flora nativa".

Uma forma de assegurar o uso econômico de modo sustentável na Reserva Legal é através do Manejo Florestal Sustentável. No artigo 17, parágrafo $1^{\circ}$ da Lei 12.651 cita-se: “Admite-se a exploração econômica da Reserva Legal mediante manejo sustentável, previamente aprovado pelo órgão competente do Sisnama, de acordo com as modalidades previstas no art. 20".

Segundo o Serviço Florestal Brasileiro (2013) o "Manejo Florestal Sustentável é a administração da floresta para obtenção de benefícios econômicos, sociais e ambientais, respeitando-se os mecanismos de sustentação do ecossistema objeto do manejo e considerandose, cumulativa ou alternativamente, a utilização de múltiplas espécies madeireiras, de múltiplos produtos e subprodutos não-madeireiros, bem como a utilização de outros bens e serviços de natureza florestal".

Na implantação do povoamento florestal em Reserva Legal, com o objetivo de se realizar o manejo florestal sustentável, é importante o uso de espécies que permitam a conservação da biodiversidade e espécies de valor econômico, o que pode requerer a necessidade de utilizar tanto espécies nativas como espécies exóticas. Na Lei Florestal no 12.651, o art. 66 descreve: “ $O$ proprietário ou possuidor de imóvel rural que detinha, em 22 de julho de 2008, área de Reserva Legal em extensão inferior ao estabelecido no art. 12, poderá regularizar sua situação, independentemente da adesão ao PRA, adotando as seguintes alternativas, isolada ou conjuntamente: I - recompor a Reserva Legal; II - permitir a regeneração natural da vegetação na área de Reserva Legal; III - compensar a Reserva Legal. O parágrafo $2^{\circ}$ do art. 66 descreve: "A recomposição de que trata o inciso I do caput poderá ser realizada mediante o plantio intercalado de espécies nativas com exóticas ou frutíferas, em sistema agroflorestal, observados os seguintes parâmetros: 1 - o plantio de espécies exóticas deverá ser combinado com as espécies nativas de ocorrência regional; II - a área recomposta com espécies exóticas não poderá exceder a 50\% (cinquenta por cento) da área total a ser recuperada. 
Dessa forma, o presente trabalho teve como objetivo realizar o levantamento das espécies florestais recém implantadas em área de Reserva Legal experimental, visando determinar a adequação desta área ao manejo florestal sustentado.

\section{METODOLOGIA}

O trabalho foi realizado na Escola Técnica Estadual - ETEC Prof. Dr. Antonio Eufrásio de Toledo, pertencente ao Centro Estadual de Educação Tecnológica Paula Souza - CEETEPS, localizada em Presidente Prudente- SP. A área experimental constou de $1950 \mathrm{~m}^{2}$, cujas coordenadas geográficas são de 22ำ10’33.98” S e 512ํ' 39.05” O, e altitude média de 491m.

O local possui temperatura anual média mínima de 14 으, média de 23,6 으 e máxima 31 으; pluviosidade média anual de 1254.9 mm e classificação climática, segundo Koeppen, como Aw, caracterizado por inverno seco e verão chuvoso (CEPAGRI, 2014). O solo da região é o Argissolo (IBGE, 2001).

O bioma local é Mata Atlântica (IBGE, 2004 a) e a Floresta é Estacional Semi-Decidual (IBGE, 2004b). Para o levantamento das espécies disponíveis, utilizaram-se os Livros: “Árvores Brasileiras volume 1 (LORENZI, 2010), Árvores Exóticas no Brasil (LORENZI, 2003) e Árvores da Floresta Estacional Semi-Decidual (RAMOS, 2008). O reflorestamento empregou o plantio tradicional em linha, espaçamento $6 \mathrm{~m}^{2}$ entre plantas e arranjo $3 \times 2 \mathrm{~m}$.

A avaliação realizou-se em setembro de 2014. Como parâmetro para avaliação, o levantamento foi baseado nas exigências previstas na Lei Florestal 12651 e da Resolução da Secretaria do Estado de São Paulo SMA 32.

\section{RESULTADOS}

Ao todo foram plantados 278 indivíduos arbóreos, sendo 173 indivíduos de espécies nativas da região $\left(1038 \mathrm{~m}^{2}\right.$ ) (62\%) (Tabela 1) intercalados com 105 indivíduos de espécies não nativas regionais (Tabela 2), incluindo espécies exóticas, em sua maioria, de valor econômico (630 $\left.m^{2}\right)(38 \%)$.

\subsection{Em relação às espécies nativas regionais}

Foram plantadas 18 espécies arbóreas regionais, de 11 famílias, sendo 8 espécies com dispersão zoocórica (44\%), 1 espécie ameaçada de extinção (6\%), 9 espécies pioneiras (50\%) e 9 espécies não-pioneiras (50\%) (Tabela 1 ). 
Tabela 1. Relação das espécies nativas regionais.

\begin{tabular}{|c|c|c|c|c|c|c|c|c|}
\hline $\begin{array}{l}\mathbf{N} \\
\underline{\mathbf{o}}\end{array}$ & Espécie & Nome científico & Família & $\begin{array}{l}\mathbf{G} \\
\mathbf{E}\end{array}$ & $\begin{array}{c}\text { Dispers } \\
\text { ão } \\
\text { Zoocóri } \\
\text { ca }\end{array}$ & $\begin{array}{l}\text { Altu } \\
\text { ra } \\
(m)\end{array}$ & $\begin{array}{l}\text { № } \\
\text { Ind } \\
\text {. }\end{array}$ & $\begin{array}{l}\text { Participaç } \\
\text { ão }\end{array}$ \\
\hline 1 & $\begin{array}{l}\text { Cabreúva- } \\
\text { vermelha }\end{array}$ & Myroxylon peruiferum & Fabaceae & $\begin{array}{l}N \\
P\end{array}$ & Não & 20 & 7 & $4 \%$ \\
\hline 2 & Olho-de-cabra & Ormosia arbórea & $\begin{array}{c}\text { Leguminos } \\
\text { ae }\end{array}$ & $\begin{array}{l}N \\
P\end{array}$ & Não & 20 & 7 & $4 \%$ \\
\hline 3 & Ipê amarelo & Handroanthus albus & $\begin{array}{c}\text { Bignoniace } \\
\text { ae }\end{array}$ & $\begin{array}{l}N \\
P\end{array}$ & Não & 30 & 9 & $5 \%$ \\
\hline 4 & Pau-ferro & Caesalpinia férrea & $\begin{array}{c}\text { Leguminos } \\
\text { ae }\end{array}$ & $\begin{array}{l}N \\
P\end{array}$ & Não & 30 & 7 & $4 \%$ \\
\hline 5 & Jequitibá-rosa* & Cariniana legalis & $\begin{array}{l}\text { Lecythidac } \\
\text { eae }\end{array}$ & $\begin{array}{l}N \\
P\end{array}$ & Não & 50 & 7 & $4 \%$ \\
\hline 6 & Saboneteira & Sapindus saponaria & $\begin{array}{c}\text { Sapindace } \\
\text { ae }\end{array}$ & $\begin{array}{l}N \\
P\end{array}$ & Sim & 9 & 9 & $5 \%$ \\
\hline 7 & Pitanga & Eugenia uniflora & Myrtaceae & $\begin{array}{l}N \\
P\end{array}$ & Sim & 12 & 9 & $5 \%$ \\
\hline 8 & Jatobá & Hymenaea courbaril & $\begin{array}{l}\text { Leguminos } \\
\text { ae }\end{array}$ & $\begin{array}{l}N \\
P\end{array}$ & Sim & 20 & 9 & $5 \%$ \\
\hline 9 & Guanandi & Calophyllum brasiliensis & Clusiaceae & $\begin{array}{l}N \\
P\end{array}$ & Sim & 30 & 5 & $3 \%$ \\
\hline $\begin{array}{l}1 \\
0\end{array}$ & Ipê verde & Cybistax antisyphilitica & $\begin{array}{c}\text { Bignoniace } \\
\text { ae }\end{array}$ & $\mathrm{P}$ & Não & 12 & 12 & $7 \%$ \\
\hline $\begin{array}{l}1 \\
1\end{array}$ & Amendoim & Pterogyne nitens & $\begin{array}{l}\text { Leguminos } \\
\text { ae }\end{array}$ & $P$ & Não & 15 & 17 & $10 \%$ \\
\hline $\begin{array}{l}1 \\
2\end{array}$ & Açoita cavalo & Luehea divaricata & Tiliaceae & $P$ & Não & 25 & 11 & $6 \%$ \\
\hline $\begin{array}{l}1 \\
3\end{array}$ & Angico vermelho & Parapiptadenia rigida & $\begin{array}{l}\text { Leguminos } \\
\text { ae }\end{array}$ & $P$ & Não & 30 & 10 & $6 \%$ \\
\hline $\begin{array}{l}1 \\
4\end{array}$ & Timboril & $\begin{array}{c}\text { Enterolobium } \\
\text { contortisiliquum }\end{array}$ & $\begin{array}{c}\text { Mimosace } \\
\text { ae }\end{array}$ & $P$ & Não & 35 & 10 & $6 \%$ \\
\hline $\begin{array}{l}1 \\
5\end{array}$ & Goiaba & Psidium guajava & Myrtaceae & $P$ & Sim & 6 & 14 & $8 \%$ \\
\hline $\begin{array}{l}1 \\
6\end{array}$ & Ingá-do-brejo & Inga vera & $\begin{array}{c}\text { Leguminos } \\
\text { ae }\end{array}$ & $P$ & Sim & 10 & 10 & $6 \%$ \\
\hline $\begin{array}{l}1 \\
7\end{array}$ & $\begin{array}{c}\text { Aroeira } \\
\text { pimenteira }\end{array}$ & Schinus terebinthifoli & $\begin{array}{c}\text { Anacardiac } \\
\text { eae }\end{array}$ & $\mathrm{P}$ & Sim & 10 & 10 & $6 \%$ \\
\hline $\begin{array}{l}1 \\
8\end{array}$ & Jaracatiá & Jacaratia spinosa & Caricaceae & $P$ & Sim & 20 & 10 & $6 \%$ \\
\hline & & & & & & & 17 & \\
\hline & Total & & & & & & 3 & $100 \%$ \\
\hline
\end{tabular}

*Ameaçada de extinção; GE - Grupo Ecológico; NP - Não Pioneira e P - Pioneira 


\subsection{Em relação aos indivíduos das espécies não nativas regionais}

Foram plantados 105 indivíduos pioneiros (60\%), 69 indivíduos não-pioneiros (40\%), sendo que nenhuma espécie pioneira constou de mais de 17 indivíduos e nenhuma espécie não-pioneira com mais de 9 indivíduos. Uma espécie constou com menos de 6 indivíduos (Tabela 2).

Tabela 2. Relação das espécies não-nativas regionais.

\begin{tabular}{|c|c|c|c|c|c|c|c|}
\hline № & Espécie & Nome científico & Família & Origem & $\begin{array}{c}\text { Altura } \\
(\mathrm{m})\end{array}$ & $\begin{array}{l}\text { Qta } \\
\text { de }\end{array}$ & $\begin{array}{c}\text { Participa } \\
\text { ção }\end{array}$ \\
\hline 1 & $\begin{array}{c}\text { Pau Brasil } \\
\text { Castanha do }\end{array}$ & $\begin{array}{c}\text { Caesalpinia } \\
\text { echinata } \\
\text { Bombacopsis }\end{array}$ & Leguminosae & Brasil & 12 & 5 & $5 \%$ \\
\hline 2 & Maranhão & glabra & Bombacaceae & Brasil & 6 & 5 & $5 \%$ \\
\hline 3 & Oiti & $\begin{array}{l}\text { Licania } \\
\text { tomentosa } \\
\text { Rheedia }\end{array}$ & $\begin{array}{c}\text { Chrysobalana } \\
\text { ceae }\end{array}$ & Brasil & 15 & 5 & $5 \%$ \\
\hline 4 & Bacuri mirim & gardneriana & Clusiaceae & Brasil & 7 & 5 & $5 \%$ \\
\hline 5 & Ingá de metro & Inga edulis & Leguminosae & Brasil & 25 & 10 & $10 \%$ \\
\hline 6 & Seringueira & $\begin{array}{c}\text { Hevea } \\
\text { brasiliensis }\end{array}$ & $\begin{array}{c}\text { Euphorbiacea } \\
\mathrm{e}\end{array}$ & Brasil & 30 & 25 & $24 \%$ \\
\hline 7 & Coloral & $\begin{array}{l}\text { Bixa orellana } \\
\text { khaya }\end{array}$ & Bixaceae & Brasil & 5 & 5 & $5 \%$ \\
\hline 8 & Mogno africano & $\begin{array}{c}\text { senegalensis } \\
\text { Annoma }\end{array}$ & & $\begin{array}{c}\text { África } \\
\text { América }\end{array}$ & 50 & 5 & $5 \%$ \\
\hline 9 & Graviola & $\begin{array}{l}\text { muricata } \\
\text { Malphigia }\end{array}$ & $\begin{array}{l}\text { Annonaceae } \\
\text { Malpighiacea }\end{array}$ & Central & 6 & 5 & $5 \%$ \\
\hline 10 & Acerola & glabra & $\mathrm{e}$ & Antilhas & 3 & 5 & $5 \%$ \\
\hline 11 & Amora & Morus Nigra & Moraceae & China & 12 & 10 & $10 \%$ \\
\hline 12 & Roma & $\begin{array}{c}\text { Punica } \\
\text { granatum } \\
\text { Azadirachta }\end{array}$ & Punicaceae & $\begin{array}{l}\text { Europa/Hi } \\
\text { malia }\end{array}$ & 6 & 5 & $5 \%$ \\
\hline 13 & $\mathrm{Nim}$ & indica & Meliaceae & $\begin{array}{c}\text { Índia } \\
\text { Índia/Indon }\end{array}$ & 18 & 10 & $10 \%$ \\
\hline 14 & Teca & Tectona grandis & Verbenaceae & ésia & 35 & 5 & $5 \%$ \\
\hline $\begin{array}{l}\text { Tot } \\
\text { al }\end{array}$ & & & & & & 105 & $100 \%$ \\
\hline
\end{tabular}

\section{DISCUSSÃO}

O plantio de espécies nativas intercalado com espécies exóticas, mesmo amparado pela lei (Lei Florestal 12.651, Art. 66, parágrafo $\S 3^{\circ}$ ), é criticado por uma parte da sociedade, devido à dupla finalidade do plantio, ou seja, auxiliar a manutenção da biodiversidade local e gerar ganhos econômicos, uma vez que poderia apenas garantir a manutenção da biodiversidade local da flora e fauna. 
No entanto, ressalta-se que mesmo que uma floresta para manejo não consiga conservar a fauna e flora, se comparado a uma flora apenas para fins de conservação, pode-se afirmar que será muito melhor, se não houvesse floresta alguma, pois a floresta para fins de manejo florestal permite a cobertura e conservação do solo e sua fertilidade, aumento na infiltração de água no solo, maior água disponível no lençol freático, formação de local para abrigo e alimentação da fauna, purificação do ar através do sequestro de carbono, redução da variação brusca de temperatura, redução de velocidade de ventos, umidificação do ar, aumento das chuvas, melhor qualidade de vida e redução de enfermidades na população. Todas essas vantagens vêm associadas à possibilidade do proprietário rural poder retirar da floresta produtos para subsistência ou comercialização, mediante autorização do órgão competente.

A quantidade e a diversidade de espécies nativas regionais exigidas em projetos de reflorestamento no Estado de São Paulo é determinada pela Resolução da Secretaria do Meio Ambiente do Estado de São Paulo - SMA 32, anexo III. As recomendações na SMA 32 são uma tentativa de buscar assemelhar os projetos às mínimas condições naturais de florestas da Mata Atlântica, contemplando espécies pioneiras e não pioneiras, espécies com dispersão zoocórica e espécies ameaçadas de extinção. O cumprimento dessa recomendação permite uma diversidade mínima de espécies, o que ajuda no bom desenvolvimento do reflorestamento, uma vez que melhora o processo de fechamento da floresta e cobertura do solo, atrai a fauna e contribui para evitar que espécies ameaçadas de extinção sejam extintas. Como resultado tem-se processos ecológicos mínimos, a garantir a autonomia e perpetuação da floresta.

A quantidade de indivíduos do reflorestamento, determinado pela Resolução da Secretaria do Meio Ambiente do Estado de São Paulo - SMA 32, anexo III, sugere a quantidade mínima e máxima de indivíduos por grupo de sucessão (pioneiros e não-pioneiros) e por espécie. Esse mecanismo é importante para evitar que um local seja dominado por uma determinada espécie e que ocorra a diversidade genética e propagação das espécies.

\section{CONCLUSÃO}

Após a realização do levantamento, observa-se que o reflorestamento obedeceu a Lei 12651 e a SMA 32, que orientam para a mínima exigência para a efetuação de um reflorestamento heterogêneo para recomposição de áreas degradadas. Por fim, é importante citar que se faz necessário práticas silviculturais e monitoramento para que ocorra o desenvolvimento das mudas e formação de uma floresta que consiga desempenhar sua função ecológica, social e econômica. 


\section{REFERÊNCIAS}

CEPAGRI. Centro de Pesquisas Meteorológicas e Climáticas Ligadas a Agricultura da Unicamp: Clima no município de Presidente Prudente-SP

< http://www.cpa.unicamp.br/outras-informacoes/clima muni 467.html>. Acesso em 20 mai 2014.

Instituto Brasileiro de Geografia e Estatística - IBGE: Mapa de biomas do Brasil - 2004a, através do site: <http://www.ibge.gov.br/home/presidencia/noticias/21052004biomas.shtm>.

Acesso em 28 ago 2014.

Instituto Brasileiro de Geografia e Estatística - IBGE: Mapa de vegetação do Brasil - 2004b, através do site: < ftp://ftp.ibge.gov.br/Cartas e Mapas/Mapas Murais/>. Acesso em 28 ago 2014.

Instituto Brasileiro de Geografia e Estatística - IBGE: Mapa de solos do Brasil - 2001, através do site: <http://mapas.ibge.gov.br/tematicos/solos>. Acesso em 28 ago 2014.

Lei Federal no 12.651 de 25 de Maio de 2012. Disponível em:< http://www.planalto.gov.br/ccivil 03/ ato2011-2014/2012/lei/l12651.htm>. Acesso em: 15 ago 2014.

LORENZI, H. Árvores Exóticas no Brasil: madeireiros, ornamentais e aromáticas. Nova Odessa, São Paulo, 2003.

LORENZI, H. Árvores brasileiras: Manual de identificação e cultivo de plantas arbóreas nativas do Brasil. Plantarum, Nova Odessa, vol. 1. 5a Ed. 2010. 384p

Resolução da Secretaria do Estado de São Paulo SMA 32. Disponível em:

< www.ambiente.sp.gov.br/legislacao/...sma/resolucao-sma-32-2014>

Acesso em 01 set 2014.

RAMOS, V. S.; DURIGAN, G. FRANCO, G. A. D. C.; SIQUEIRA, M. F.; RODRIGUES, R. R. Árvores da Floresta Estacional Semidecidual: Guia de Identificação de espécies. São Paulo. Editora da Universidade de São Paulo: Biota/Fapesp, 2008. 320 p.

Serviço Florestal Brasileiro. Florestas do Brasil em resumo - 2013: dados de 2007-2012. Brasília: SFB, 2013. 188 p. Disponível em: < http://www.florestal.gov.br/publicacoes/tecnicocientifico/florestas-do-brasil-em-resumo-2013>. Acesso em: 19 ago. 2014. 